\title{
THE GENDER AND SIDE ASYMMETRY OF LENGTH OF THE STYLOID PROCESS
}

\author{
Jan HT Smit ${ }^{1}$, H Breen ${ }^{2}$ \\ ${ }^{1}$ Department of Anatomy, School of Medicine, Faculty of Health Sciences, University of Namibia, \\ Windhoek, Namibia. jsmit@unam.na \\ ${ }^{2}$ School of Medicine, Queens University of Belfast, Belfast, Northern Ireland. \\ Correspondence to Prof. Jan H T Smit, PO Box 87188, Eros, Windhoek, Namibia. Tel.: +264 61 \\ 2065099; jsmit@unam.na
}

\begin{abstract}
The styloid process is a sharp bony projection, at the base of the skull, and part of the temporal bone. Muscles and ligaments are attached to this process, but they are rarely of any clinical significance unless the styloid process is fractured or severely elongated. Pathology of the styloid process is referred to as Eagle's syndrome. This was after a publication by Eagle (1937) in which he reported a $4 \%$ prevalence of elongated styloid processes. Later studies reported much higher percentages of elongated processes. The aims of this study was to investigate the mean length of the styloid process and compare this with what is accepted as the "normal" length after the Eagle publication. The study also looked at evidence of asymmetry between the two sides within the same specimen. Comparison in the lengths between the two sexes were also made. Forty-five styloid processes from 28 different individuals were measured for comparison. The sample group consisted out of 18 males- and 10 female subjects. The lengths of the styloid processes varied from $7.17-50.54 \mathrm{~mm}$, with a mean of $27.48 \mathrm{~mm}$. Styloid processes were on average $0.87 \mathrm{~mm}$ longer on the right side and $3.12 \mathrm{~mm}$ longer in the male specimens. This mean length of $27 \mathrm{~mm}$ supports the claim by Eagle that the "normal" length is around $25 \mathrm{~mm}$. Ten out of 25 individuals (40\%) exhibited "elongated" styloid processes measuring over $25 \mathrm{~mm}$. These findings were higher than those reported by Eagle. Elongated styloid processes are clinically important in order to make the correct diagnosis.
\end{abstract}

Keywords: Styloid process; Eagel's Syndrome; Elongated (abnormal length) styloid process.

\section{INTRODUCTION}

The styloid process is a thin, "needle-like" bony projection found anteromedial to the mastoid process and projecting from the basal part of the temporal bone. It is a common site for muscle attachment. It is slightly curved anteriorly and forms part of the posterior wall of the retromandibular space. Important relations of this structure include the jugular and stylomastoid foramina, their content as well as the muscles attached to it. A normal styloid process will nestle between the internaland external carotid arteries. Any medial or lateral deviation or elongation of the styloid process, may lead to impingement or entrapment of any of the attached muscles, vessels or nerves (Eagle, 1948).

The styloid process is rarely associated with any clinical significance unless it is elongated, fractured or structures attached to it becomes ossified (Drake et al., 2010). In such an event, the presence of a bony spike amongst the soft tissue of the pharynx and neck can lead to impingement of the neurovascular structures. This can lead to a wide range of symptoms which varies from nonspecific facial- or neck 
pain to neurological deficits caused by cerebral ischaemia (Pereira et al., 2007; Farhat et al., 2009). Clinical symptoms associated with the styloid process are referred to as Eagle's Syndrome. Watt Eagle was an otolaryngologist in the early nineteen hundred who published the first article on these symptoms in 1937. Eagle however accredited the first descriptions of these symptoms to Weinlecher in 1872.

The prevalence of elongated styloid processes is uniformly accepted to be around $4 \%$. This came from the original publication by Eagle, but do not specify whether it refers to bilateral or unilateral measurements (Eagle, 1937; Steinnmann, 1968). Generally, a length of $25 \mathrm{~mm}$ is considered as the "normal" length of the styloid (Pereira et al., 2007). Any styloid process longer that $25 \mathrm{~mm}$ can then be considered as elongated (Eagle, 1937). The aim of this project was to investigate the mean styloid process length in a small cadaveric group of 18 specimens combined with 10 orthopantomograms of patients from the Dental school in Belfast.

\section{MATERIALS AND METHODS}

The cadaver specimens that were used for this study, were 18 individuals that were obtained to be used in the dissection room of the Anatomy Department at Queens University in Belfast. These bodies were all obtained through the Body Donation Scheme in Northern Ireland. The regulatory body managing all donations and the consent issues of human tissue, is the Human Tissue Authority of England since 2004. All the bodies were embalmed on site by the mortuary technician. The embalming was done through gravity induced perfusion using the right common carotid artery in the neck.
Ten orthopantomograms (dental X-rays of panoramic view) were obtained from the School of Dentistry at the Royal Victoria Hospital in Belfast. These X-rays were included in our investigation to enlarge our sample size and for comparison reasons. The orthopantomograms were from people of the same population group and areas where the cadavers originally came from. Our sample group therefore existed out of 28 individuals, all from in and around the Belfast area in Northern Ireland.

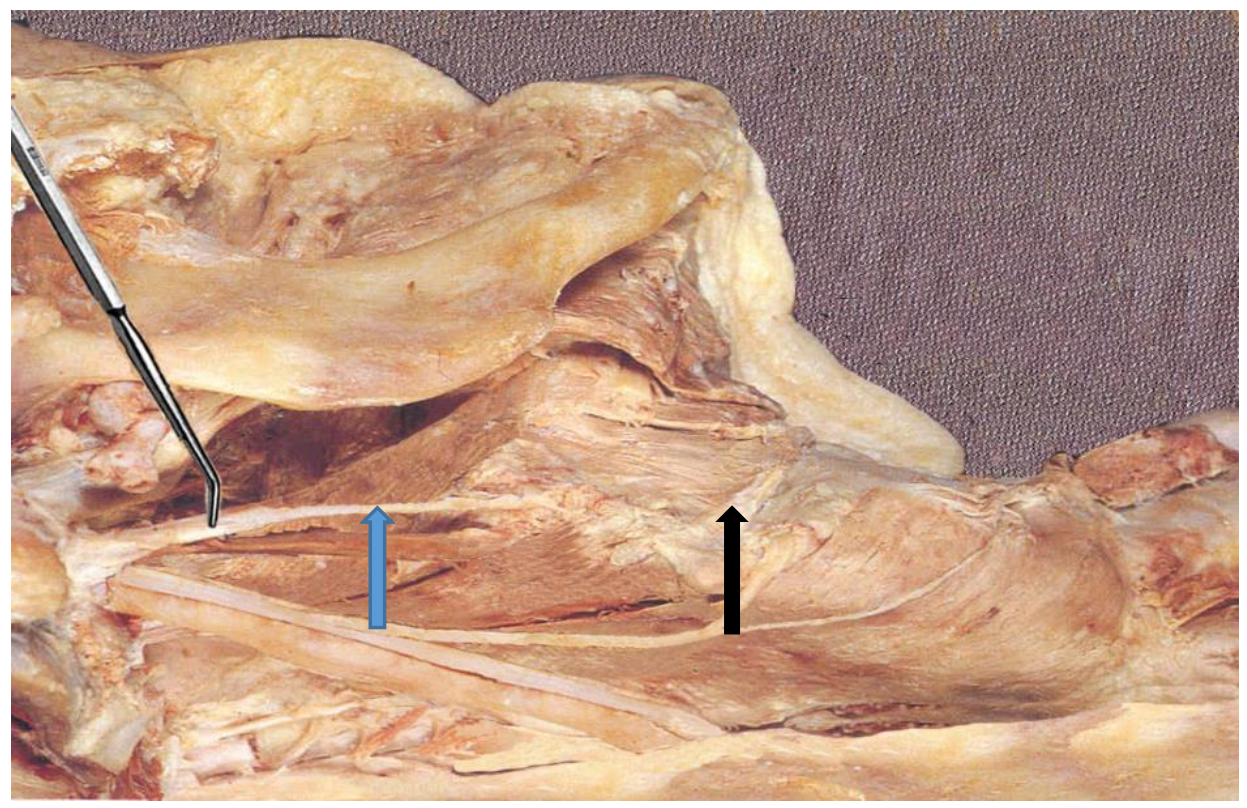

Figure 1: Dissection showing styloid process with probe, stylohyoid ligament (blue) and Hyoid bone (black).

The cadavers that were used for this study, was already partially dissected by the second year Medical students. The muscles of mastication, facial muscles, parotid gland, 
blood vessels and nerves were already exposed by dissection. The mandible was sectioned into two halves and separately removed by dislocating the temporomandibular joints. This allowed exposure of the tongue and oral cavity from the lateral side.

Each head was rotated through approximately 30 degrees towards the contralateral side and held in an elevated position by a cervical autopsy support block. The soft tissue overlying the area of interest (remaining fascia, parotid gland, masticatory- and facial muscles, blood vessels and nerves) were all carefully removed by dissection, to expose the entire length of the styloid process. This was done by using scalpel, scissors and toothed forceps and with the aid of a dissection magnifying glass (X5 magnification). Careful digital palpation of the tip of the styloid process and of the stylohyoid ligament (Figure 1) was done manually, to evaluate if ossification of the ligament was obvious. All the muscle- and ligament attachments to the styloid process were carefully removed through dissection. The whole styloid process, from the tip to the junction (ridge) between tympanohyal and stylohyal, was now exposed and ready to be measured.

A Duratool digital calliper (product code D00377, range $0-150 \mathrm{~mm}$ ) was used to measure the length of the styloid processes. The measurement was in millimetres and correct to two decimal places. The length of the styloid process was measured twice, and the average was taken, if the readings were different. The orthopantomograms obtained were viewed on a standard-brightness Enstar light box (Xray Accessories Ltd). The images on the orthopantomograms were the same as the actual sizes of the tissue that were scanned. The same calliper was used with the same technique of taking two measurements with an average length, if it was required. All the recordings were made by the same person and the data were entered into a SSPS statistical software package for analysis.

\section{RESULTS}

In total, 28 individuals were used for analyses in this study. Eighteen measurements were from cadaveric specimens and the remaining 10 were measurements from radiographs of elderly people attending the Clinic at the Dental School in Belfast. Forty five individual styloid processes were measured and analysed for this study. Out of the 45 styloid processes measured, 25 were longer than $25 \mathrm{~mm}$. This represents $55.5 \%$ of the measured sample. Out of the 25 individuals with at least one measurable styloid process, $10(40 \%)$ had bilateral styloid processes longer than $25 \mathrm{~mm}$. Four individuals had unilateral styloid processes longer than $25 \mathrm{~mm}(16 \%)$ and one individual had one styloid process longer than
$25 \mathrm{~mm}$ on the one side and no styloid on the other side. This gave us 15 out of the 25 individuals with at least one styloid longer than $25 \mathrm{~mm}$ ( $60 \%$ of the measured sample) that might be at risk of signs of Eagle's syndrome.

The mean length of the styloid processes in this study was calculated at $27.48 \mathrm{~mm}$. The mean lengths of the male styloid processes were $28.59 \mathrm{~mm}$ (standard deviation of 1.69). The mean lengths of the female styloid processes were $25.47 \mathrm{~mm}$ (standard deviation of 2.33). This means the styloid processes of the males were on average $3.12 \mathrm{~mm}$ longer than those of the females (Figure 4). 


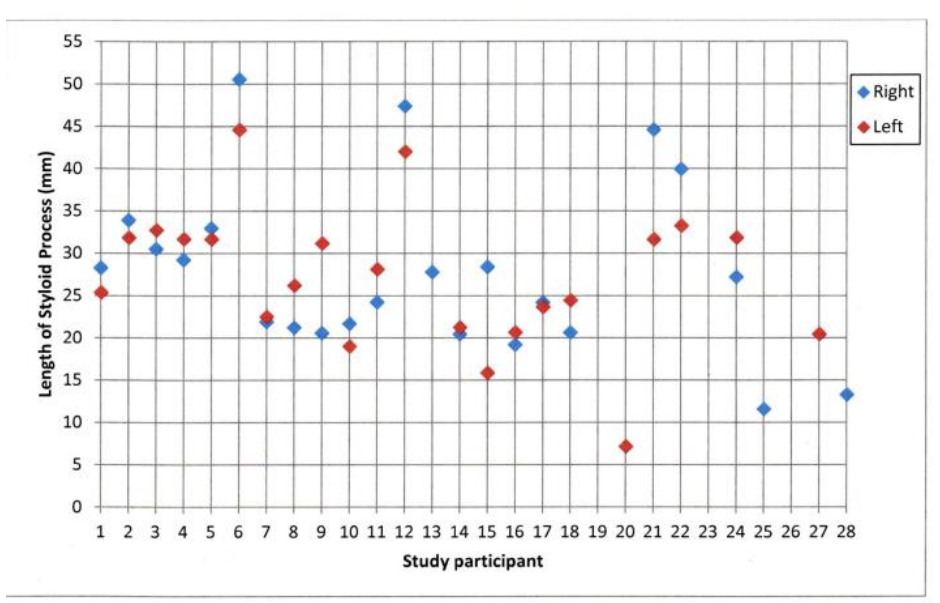

Figure 2: $\quad$ Scatter graph showing the different lengths of styloid processes

There is very little difference in the lengths on the two sides (Figure 3). The mean length of the styloid processes on the left side was $27.90 \mathrm{~mm}$ (standard deviation of 1.66), compared to the mean length on the right side which was $28.57 \mathrm{~mm}$ (standard deviation of 2.31). This means the styloid processes on the right side were $0.67 \mathrm{~mm}$ longer than those on the left sides. On the right side, we had one "outlier" which is indicated on the graph with $0^{5}$. This was cadaver 1106 which had a right sided styloid process measuring $50.54 \mathrm{~mm}$. In this study we had 28 individuals. There were 18 males and 10 females. Out of the 18 males, 16 had at least one measurable styloid process. Out of the 10 females, 9 had at least one measurable styloid process. Therefore, the total number of measurable styloid processes were 45 . Of these, 29 styloid processes were from males and 16 styloid processes were from female specimens.

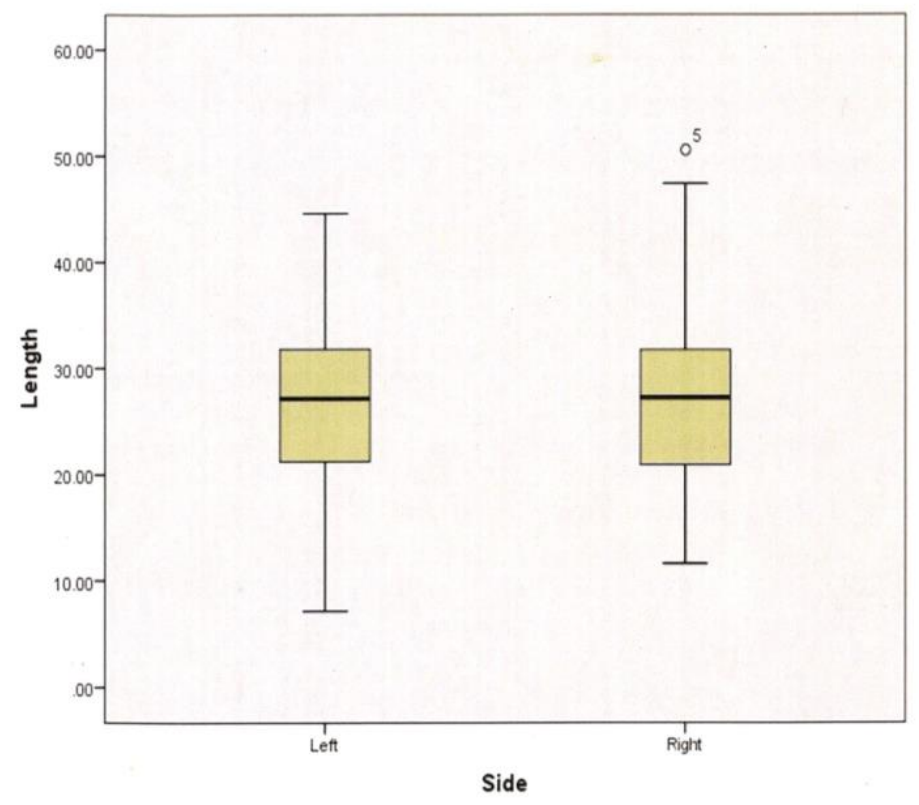

Figure 3: Boxplot comparing the lengths of the styloid processes on both sides. 


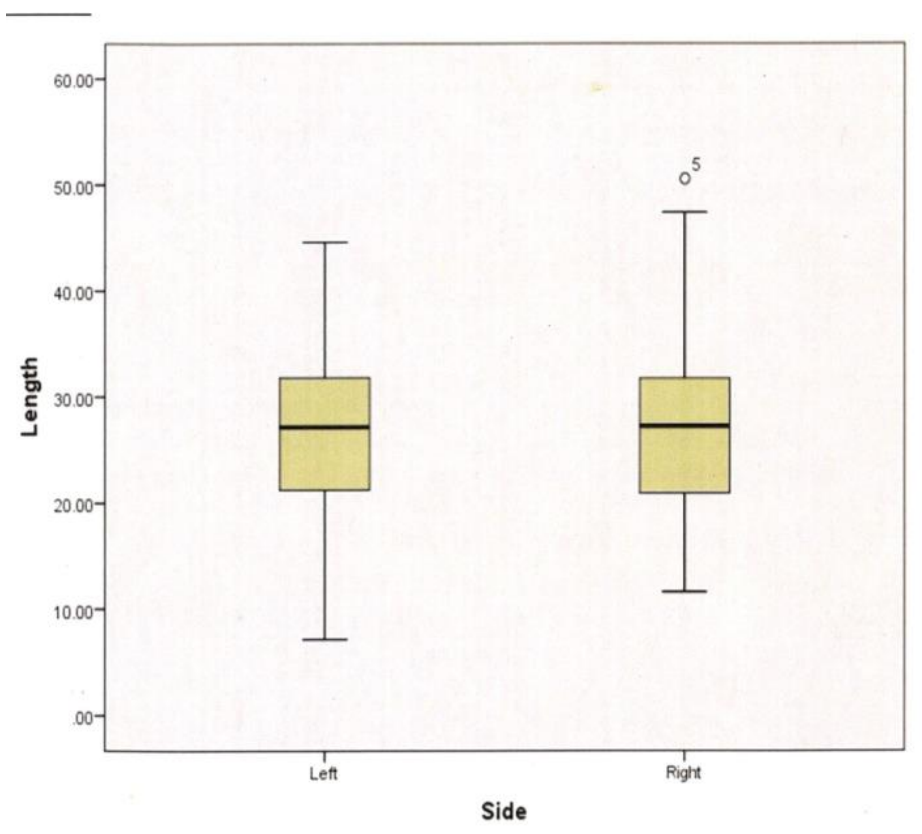

Figure 4: Boxplot comparing the lengths of the styloid processes; male versus female

The male group was larger than the female group. In the male group, there were three "outliers" that measured $50.54 \mathrm{~mm}, 47.39 \mathrm{~mm}$ and $44.62 \mathrm{~mm}$. These were values $>13.14 \mathrm{~mm}$ outside the value of the $3^{\text {rd }}$ quartile and can be seen above the graph (Figure 6).

\section{DISCUSSION}

The aim of this study was to investigate whether the $25 \mathrm{~mm}$ that is considered as the average or normal length of the styloid process was the actual value or not (Eagle, 1937; Gossman and Tarsitano, 1977; Correll et al., 1979; Chase, 1986). The high prevalence of elongated styloid processes $(>25 \mathrm{~mm}$ ) reported (Kaufman, 1970; Moffat et al., 1977; O'Carroll, 1984; Keur et al., 1986), suggested that this "normal" length value should be bigger/longer. Our data shows that more than half of the cases $(55.5 \%)$ had styloid processes that measured longer than $25 \mathrm{~mm}$. This correlated with the findings of the group mentioned above (Kaufman, 1970; Moffat et al., 1977; O'Carroll, 1984; Keur et al., 1986). The variety in lengths were between $7.17 \mathrm{~mm}-50.54 \mathrm{~mm}$ with a mean length of $27.48 \mathrm{~mm}$. This value is not significantly far from the accepted $25 \mathrm{~mm}$ described in the original article by Eagle. If we accept natural variations to be $10 \%$, and that the length of the styloid process is $25 \mathrm{~mm}$, then the variation in length can be between $22.5 \mathrm{~mm}$ and $27.5 \mathrm{~mm}$. So, clinically and statistically not a significant difference between our finding and that of Eagle in 1937.
In Eagle's publication (1948), he stipulated that a styloid process of "normal" length $(25 \mathrm{~mm})$, cannot be palpated in the tonsillar fossa. So, any styloid process palpable in the fossa, can be classified as elongated! With our findings, this will be the case in $55.5 \%$ of styloid processes that were measured. With the measurements obtained in our study, it became clear that there is considerable differences between the lengths of the styloid processes on the two sides (Worth, 1963; O'Carroll, 1984; Keur et al., 1986).

In order to compare the lengths on the two sides, we could only use individuals with bilateral measurable styloid processes. There were 20 individuals meeting this criterion. Within this group, the greatest difference between the two sides was $12.95 \mathrm{~mm}$. The smallest difference was only $0.56 \mathrm{~mm}$. The mean difference between the two sides in this "smaller" group was $4.42 \mathrm{~mm}$ compared with the mean difference in the whole group (all the measurable styloid processes) which was $0.67 \mathrm{~mm}$. So, therefor not a significant big difference. There was also no fixed pattern to which side was consistently the longest. The 
mean length of the right sided styloid processes was $0.89 \mathrm{~mm}$ longer than their counter partners on the left side. Therefor not clinically significant and no defined side dominance.

The other criteria we looked at, was the differences between the lengths of the styloid processes in the different gender groups. This was arguably the most interesting issue to address with this study. Not only is there no consensus in the literature on sexual dimorphism regarding the styloid process lengths (Eagle,1949; Steinmann, 1977; Strauss et al., 1985; Monsour and Young, 1986; Camrada et al., 1989; Prasad et al., 2002), but also with regarding other anatomical variations such as the pelvic- and orbital foramina sizes (Salerno et al., 2006; Agthong et al., 2005). Of the 18 male individuals, 13 had bilateral measurable styloid processes and 3 had only one measurable styloid process. Two individuals had no styloid processes that could be measured to satisfaction. Of the 10 female individuals, 7 had bilateral measurable styloid processes and 2 had only one measurable styloid process. One individual had no styloid process that could be measured to satisfaction. Of the final number of 45 measurable styloid processes, 29 processes were from males and 16 processes were from females. For this comparison, we used all the measurable styloid processes.

The mean length of the male styloid processes was $28.59 \mathrm{~mm}$ (standard deviation of 1.69) and the mean length of the female styloid processes was $25.47 \mathrm{~mm}$ (standard deviation of $2.33 \mathrm{~mm}$ ). Therefor the male styloid processes were on average $3.12 \mathrm{~mm}$ longer than those of the female styloid processes. These findings are not very significant clinically and can be accepted as normal between gender groups. Male individuals tend to be bigger and more muscular than their female counterparts.

In conclusion this study we found that in $55.5 \%$ the styloid processes were elongated though all the cases were asymptomatic. Clinicians however needs to be aware of possible symptoms in order to make the correct diagnosis and prescribed the best treatment to the patient.

\section{REFERENCES}

1. Agthong $S$ et al. (2005) Anatomical variations of the supraorbital, infraorbital and mental foramina related to gender and side. Journal of Oral and Maxillofacial Surgery. 63(6):800-4.

2. Camrada AJ et al. (1989) Stylohyoid chain ossification: a discussion of etiology. Oral Surgery Oral Medicine Oral Pathology.67(5): 508-20.

3. Chase DC et al. (1986) Eagle's Syndrome: A comparison of intraoral versus extraoral surgical approaches. Oral Medicine Oral Surgery Oral Pathology. 62(6):625-9.

4. Correll RW et al. Mineralization of the styloid-stylomandibular ligament complex. A radiographic incidence study. Oral Surgery Oral Medicine Oral Pathology. 48(4): 286-91.

5. Drake R, Vogel AW, Mitchell AWM (2010) Gray's Anatomy for Students. ${ }^{\text {nd }}$ ed. Edinburgh: Churchill Livingstone Elsevier.

6. Eagle WW (1937) Elongated Styloid Processes. Report of two cases. Archives of Otolaryngology. 25(5):584-7.

7. Eagel WW (1948) Elongated Styloid processes. Further observations and a new syndrome. Archives of Otolaryngology. 4(5):630-40.

8. Eagle WW (1949) Symptomatic elongated styloid processes. Report of two cases of styloid process-carotid artery syndrome with operation. Archives of Otolaryngology. 49(5): 490-503.

9. Eagle WW (1958) Elongated styloid processes. Symptoms and treatment. Archives of Otolaryngology. 67(2):172-6.

10. Farhat H I et al. (2009) Eagle syndrome as a cause of transient ischaemic attacks. Journal of Neurosurgery. 110(1):90-3.

11. Gossman JR and Tarsitano JJ (1977) The stylo-stylohyoid syndrome. Journal of Oral Surgery. 35(7):555-60. 
12. Kaufman SM et al. (1970) Styloid process variation. Radiologic and clinical study. Archives of Otolaryngology. 91(5):460-3.

13. Keur JJ et al. (1986) The clinical significance of the elongated styloid process. Oral Surgery Oral Medicine Oral Pathology. 61(4):399-404.

14. Lavine MH et al. (1968) Calcification of the stylohyoid ligament. Oral Surgery Oral Medicine Oral Pathology. 25(1):55-8.

15. Moffat DA et al. (1977) The styloid syndrome: Aetiological factors and surgical management. Journal of Laryngology and Otology. 91(4):279-94.

16. Monsour PA and Young WG (1986) Variability of the Styloid process and stylohyoid ligament in panoramic radiographs. Oral surgery Oral medicine Oral Pathology. 61(5):522-6.

17. O'Carroll MK (1984) Calcification in the stylohyoid ligament. Oral Surgery Oral Medicine Oral Pathology. 58(5):617-21.

18. Omnell KAH et al. (1988) Ossification of the human stylohyoid ligament. A longitudinal study. Oral Surgery Oral medicine Oral Pathology Oral Radiology and Endodontology. 85(2): 22632.

19. Pereira FL et al. (2007) Styloid-Stylohyoid syndrome: literature review and case report. Journal of Oral and Maxillofacial Surgery. 65(7):1346-53.

20. Prasad KC et al. (2002) Elongated styloid process (Eagel's Syndrome): A clinical study. Journal of Oral and Maxillofacial Surgery .60(2): 171-5.

21. Salerno $G$ et al. (2006) Magnetic resonance imaging pelvimetry in 186 patients with rectal cancer confirms overlap in pelvic size between males and females. Colorectal disease. 8(9): 772-6.

22. Snell RS (2006) Clinical Anatomy by Systems. Philadelphia; Lippincott Williams and Wilkins.

23. Steinmann EP (1968) Styloid syndrome in the absence of an elongated styloid process. Acta Otolaryngology. 66(4): 347-56.

24. Strauss $M$ et al. (1985) Elongated styloid process syndrome: Intraoral versus extraoral approach for Styloid surgery. Laryngoscope. 95(8):976-9.

25. Williams JV et al. (2011) Eagel's Syndrome: a novel surgical approach to the styloid process using a preauricular incision. Journal of Oral Maxillofacial Surgery. 69(6):1617-22. 